\title{
X-ray diagnosis of esophageal cancer
}

\begin{abstract}
Provides analysis of $\mathrm{x}$-ray diagnosis of esophageal cancer, ranging from routine $\mathrm{x}$-rays of the body and ending at $\mathrm{CT}$ against the backdrop of the introduction of gas into the mediastinum. Topografoanatomicheskie highlights the difficulties in distinguishing cancerous tumors of the esophagus in the germination of surrounding organs and tissues that sharply hampers not only perform radical surgery, but also the development of algorithm of conservative treatment. Stresses the added value of pnevmomediastinografii to clarify the nature of the invasive growth of cancer of the esophagus.
\end{abstract}

Keywords: esophagus cancer, invasion, diagnostics
Volume 5 Issue 6 - 2018

\section{Shaposhnikov Veniamin Ivanovich \\ Department of Oncology, Russia}

Correspondence: Shaposhnikov VI, Department of Oncology with a course of radiation Diagnostics and therapy the NIGHT, Kuban Medical Institute, Krasnodar, Russia, Email79183445404@yandex.ru

Received: July 30, 2018 | Published: November 26, 2018

\section{Introduction}

While working in various ontological hospitals in Kazakhstan, Ukraine and Russia took stage score diagnostic capabilities also go other x-ray method. If Kazakhstan (Kzyl-Orda regional Oncology Center) it was a normal $\mathrm{x}$-ray graphs and the esophagus, then in Ukraine (Kyiv n/and rentgenoradiologicheskij and Oncology Institute) were already applied tomografografija, rentgenokinematografija, double contrast of the esophagus after the introduction of oxygen into the mediastinum, in Russia (Krasnodarskie krajonkodispanser, regional hospital, emergency hospital) added to computed tomography. I must say that in all of these medical institutions concentrated a large number of patients with cancer of the esophagus. In KzylOrda because of provincial differences (esophageal cancer ranks first among ontological diseases), in Ukraine-by directing patients from all regions, and in the Kuban region from all areas. This explains the large number of patients with the disease, which has been under our supervision. It should be emphasized that esophageal cancer is among the most severe of oenological processes. ${ }^{1-3}$ The life expectancy of the first symptoms of the disease and to death is 7-12 months. ${ }^{2-5}$ Extension of the life of the patient prior to 2.5 years is considered an achievement. ${ }^{3}$ Such aggression of this disease can be explained by peculiarities of the localization of the esophagus in the mediastinum, close contact with zhiznennovazhnymi authorities, resulting in the rapid germination of cancer beyond its own tissues as well as metastasis. ${ }^{1,7}$ Early diagnosis of this tumor can successfully fight for the extension of the life of the patient. ${ }^{4}$

\section{The purpose of the study}

Evaluate the diagnostic capabilities of x-ray techniques, which are most often applied in the clinic in the diagnosis of esophageal cancer.

\section{Material and methods}

Of the 711 patients aimed at medical institutions listed age was from 18 to 93 years. The youngest of them was a resident of Kazakhstan. Men were almost 2.5 times more than women. All of them were in a State of dramatic mental oppression, up to complete indifference to their fate. And, as a rule, it is easy to agree on any medical manipulations. During the initial screening and diagnosis of esophagus picture was installed at 591(83.1\%) patient. But these methods allow you to catch more vibrant changes in the body. They are only a few passing moments captures barium mass through the lumen of the body, reflecting the nature and type of contractions inherent in one form or another, does not reflect the nature of the tumor growing in the adjacent organs and tissues. This requires additional research methods. Now for this purpose are widely resorted to computed tomography. But this method is in close contact with the esophagus anatomically normal trachea, aortic arch top hollow Vienna and other organs and tissues can lead to diagnostic radiologist error can take contact for tumor invasion, and vice versa. For this purpose you want to bundle contact fabric that is achieved by introducing into the mediastinum gas, i.e. recourse to pnevmomediastinografii. The most common routes of gas in the mediastinum (usually carbon dioxide) are methods of Reeves and Kazan. When the first of them, oxygen in the volume $1500-3000 \mathrm{ml}$, using prikopchikovoj puncture, first introduced in the retroperitoneal space, where gas via 30-40 minutes penetrates the back mediastinum, pushes each other organs and tissues. The second is picture via jugular clipping in front of the mediastinum is blown $500-1000 \mathrm{ml}$ of gas, which then penetrates the back mediastinum. X-rays through 30-40 minutes. With cancer of the lower third of the esophagus also resorted to the introduction of oxygen (up to $1000 \mathrm{ml}$ ) free abdominal cavity (pnevmoperitoneum) followed by double or triple contrast that dramatically increased the contrast of the abdominal organ and Cardiac stomach. These techniques were performed at 260 patients. After the introduction of gas into the mediastinum used to scan and tomofljuorografiju, and is currently computed tomography. Some other methods, including rentgenokinematografija, are rarely applied due to technical complexity of manipulation.

\section{Results}

Of the 260 patients, which was introduced by gas or in the mediastinum, or into the abdominal cavity, with the subsequent, or dual (introduction only barium masses in the lumen of the esophagus) or triple (introduction of barium and with inflation lumen body inside using probe) have been obtained the following results. At 27(13.8\%) from 260 to exclude the germination of esophageal cancer in adjacent organs and tissues, and then perform the radical surgery. At 16(6.1\%) patients with complaints bring on dysphagia, install benign nature of this symptom, including: 8-deviation of the ösophagus, 3-like constriction, 4-diverticula (Figure 1 \& Figure 2).

\section{Conclusion}

In determining operability esophageal cancer the most informative place can be considered a pnevmomediastinografii. Got gas in the mediastinum pushes tissues and helps define their mobility. 


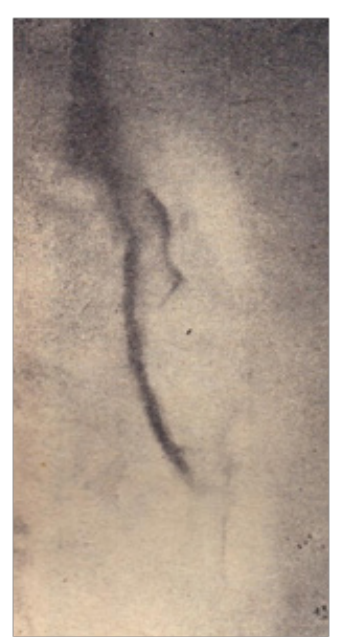

Figure I Tomograms of the esophagus, the affected cancerous growth in the middle of his third. Study performed after the introduction of gas into the mediastinum. Oblakovidnaja shadow is visible tumor, surrounded by gas. Correct diagnosis was confirmed during surgery.

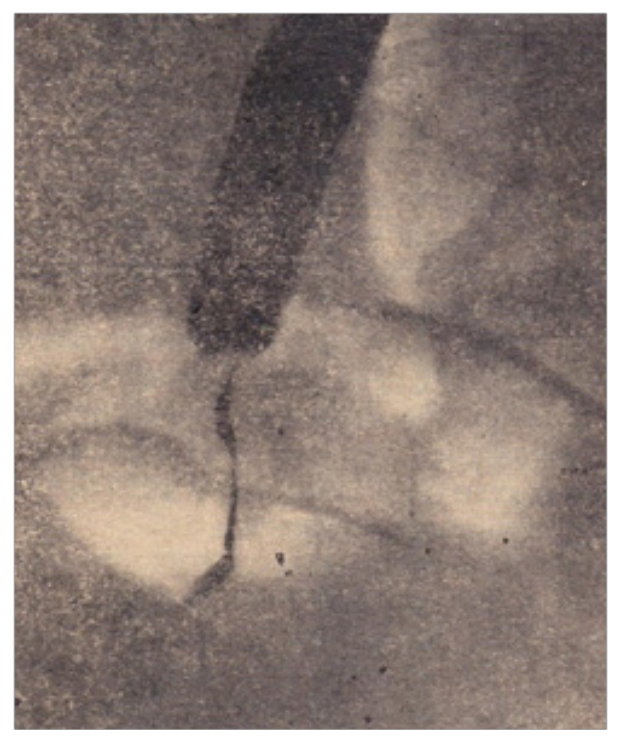

Figure 2 Radiographs of the esophagus. Cancer of the lower third of the body. The study made after the imposition of pneumoperitoneum. It is clearly visible that the tumor will not germinate in the diaphragm and liver. Correct diagnosis was confirmed during surgery

\section{Acknowledgments}

None.

\section{Conflicts of interest}

The author declares that there is no conflicts of interest.

\section{References}

1. Krejzberg GY. To the question of the course of esophageal cancer. State Institute of advanced training of physicians. 1962;32:35-37.

2. Masjukova EM. Mediastinografija in the diagnosis of diseases of the esophagus. Proceedings of the XXVII of the all-Union Congress of surgeons. 1962:112-113.

3. Starikov VI. Die esophageal Krebs: Diagnose und Perspektiven der Behan lung. International medizinischen Fachzeitschrift. 2006;12(1):66-70.

4. Chernousv AF. Esophageal Surgery. Medizin. 2000:350.

5. Shevchenko IT, Shaposhnikov VI. Esophageal Krebs. Medizin. 1972:124.

6. Berrisford RG. Short-term otitcomes following total minimally invasive oesophagectomy. Br J Surg. 2008;95(5):602-610.

7. A Das, V Singh, DE Fleischer, et al. A Comparison of Endoscopic Treatment and Surgery in Early Esophageal Cancer. An Analysis of Surveillance Epidemiology and End Results Data. Am J Gastroenterol. 2008;28:286-292. 